Orbis Tertius, vol. XXIV, nº 30, e132, noviembre 2019-abril 2020. ISSN 1851-7811

Universidad Nacional de La Plata

Facultad de Humanidades y Ciencias de la Educación

Centro de Estudios de Teoría y Crítica Literaria

\title{
Vigencia: la trama cultural de una revista del "Proceso" 1
}

\author{
Martin Servelli \\ Universidad de Buenos Aires, Argentina \\ servelli@gmail.com
}

\section{RESUMEN:}

Este trabajo presenta una indagación pormenorizada de la revista Vigencia (1977-1985), una publicación de carácter políticocultural vinculada a la Universidad de Belgrano, con el propósito de develar la compleja trama cultural de un medio afín al gobierno militar, en el que se expresaron posiciones de vanguardia en el campo literario.

Palabras clave: Revistas, Intelectuales, Gobierno militar, Campo literario.

\section{Aвstract:}

This paper presents a detailed inquiry of the magazine Vigencia (1977-1985), a political-cultural publication linked to the University of Belgrano, with the purpose of revealing the complex cultural weft of a periodical related to the military government, in which avant-garde positions in the literary field were expressed.

KEYWORDS: Magazines, Intellectuals, Military government, Literary field.

\section{1: GUERRA DE POSICIONES EN EL CAMPO LITERARIO}

Para muchos docentes, críticos e historiadores de la literatura argentina el nombre de la revista Vigencia (1977-1985) remite a un artículo casi mítico de César Aira, "Novela argentina: nada más que una idea", nada fácil de conseguir, en el que un joven e ignoto Aira juzgaba con manifiesta hostilidad la producción novelística contemporánea de los escritores “jóvenes”, con un énfasis especial en Respiración artificial (1980), de Ricardo Piglia: "una de las peores novelas de su generación" (1981a, p. 58). El dato lo había difundido el excelente estudio de Sandra Contreras sobre la obra de Aira, donde además se añadía que la publicación del artículo antecedía en dos meses a la aparición de Ema la cautiva (1981) -su segunda novela-, con lo cual su autor resultaba prácticamente un arribista en el panorama de las letras locales (Contreras, 2002, p. 26).2 Pero la de Aira no era una intervención aislada en un periódico indistinto. El artículo tramaba un frente de ataque con otros publicados en este mismo medio gráfico en particular: Vigencia, una revista mensual perteneciente a la Universidad de Belgrano, por cuya editorial Aira publicaría su próxima e inminente novela.

Podría imaginarse que la recepción de un texto tan revulsivo no estuvo exenta de polémicas, si se toma en cuenta el número de los autores imputados por Aira de convertir a la novela argentina en "una especie raquítica y malograda” (1981ª, p. 55): Luisa Valenzuela, Carlos Arcidiácono, Ramón Plaza, J. C. Martini Real, Ernesto Schóo, Fernando Sorrentino, Rubén Tizziani, Pacho O’Donnell, Fernando Sánchez Sorondo, Rodolfo Rabanal, Jorge Asís, Beatriz Guido, Roberto Fontanarrosa y Ricardo Piglia. Pero, sobre todo, si se considera la notoriedad alcanzada por dos de ellos: nada menos que Jorge Asís, el autor del mayor suceso editorial de los años de la dictadura, Flores robadas de los jardines de Quilmes (1980), que a un año de su publicación ya había agotado siete ediciones e iba camino a superar los cien mil ejemplares vendidos hacia 1984 (de Diego, 2007, p. 126); y Ricardo Piglia, cuya novela, Respiración artificial, había saltado en apenas seis meses a la lista de best sellers de Clarín con cinco mil ejemplares vendidos (Piglia, 2017, p. 141).

La reciente publicación del tercer tomo de Los diarios de Emilio Renzi, de Ricardo Piglia, actualiza la polémica al exhibir el malestar que produjo el artículo de Aira. La tensión va más allá de una confrontación de poéticas, como puede advertirse en la insistencia con que Piglia remite el artículo a la revista Vigencia y señala los vínculos de esta con la dictadura militar, según se lee en la entrada del diario fechada al 5 de agosto de 1981 
(el día posterior a la salida del número de Vigencia que contenía el artículo): "Me llama Rabanal intrigado por los ecos de un artículo sobre la narrativa actual, escrito por un sirviente de O.L. en la revista de la cultura oficial Vigencia, que trabaja para el nuevo consenso del general Viola” (2017, p. 145). Mientras que la crítica de Aira transcurre por andariveles literarios (sus principales argumentos son que Piglia no proviene de Arlt, su maestro es Sábato; la novela Respiración artificial está construida en base a dos o tres situaciones tópicas; todo el resto son opiniones, juicios críticos, ajustes de cuentas y discusiones ganadas de antemano), Piglia, en la engañosa intimidad de su diario destinado a la publicidad, sitúa la disputa en otro terreno, determinado por las posiciones políticas -además de las estéticas- en el campo intelectual. En su réplica, además de involucrar a la revista $V$ igencia, introduce un nuevo actor en la disputa, el escritor Osvaldo Lamborghini cuyas iniciales anota, a quien atribuye la autoría intelectual de la embestida en su contra. Dos días después, la entrada del diario de Renzi registra:

Y ahora, en la revista Vigencia, donde la barra de la Editorial de Belgrano trata de borrar a los escritores que han escrito acá y ellos se postulan cono la nueva cultura -cínica y paródica- surgida en los años de la peste (el objetivo soy yo, recordar la charla con O.L. en la terminal). En una entrevista César A. dijo que yo tenía cara de policía. Desde luego son tonterías, acusaciones, maniobras costumbristas de literatura vigilante, que sólo alegran a los graciosos del "Premio Coca-Cola en las Artes y las Letras" que ganó Enrique F. promovido por la cultura oficial para presentar a la nueva generación (Piglia, 2017, p. 146).

La cita amplía la identidad del frente de ataque: ya no un "sirviente" de Lamborghini -Aira-, sino una "barra" de escritores pertenecientes a la Editorial de Belgrano (el otro proyecto contemporáneo a Vigencia con el que la Universidad de Belgrano aumentaba su presencia institucional en el espacio académico y cultural del país), encabezada por [Rodolfo] Enrique Fogwill, reciente ganador del premio Coca-Cola por sus cuentos incluidos en Mis muertos punk (1980). La aludida charla con Osvaldo Lamborghini también figura en Los diarios.... Tres meses antes de la entrada anterior, en mayo de 1981, Piglia había anotado un encuentro casual con Lamborghini en la terminal de ómnibus, donde este le había comentado sobre un pedido formulado por Gabriela Massuh (entonces secretaria de redacción de Vigencia para los temas de "Cultura y Tiempos Modernos") para escribir una nota sobre Asis y Piglia, las dos "líneas enfrentadas de la literatura actual". En esa charla en el bar de la estación, entre copas de coñac y vino blanco, Lamborghini habría dejado deslizar una frase cargada de sobrentendidos, que Piglia anotó en estilo directo: "Pero en realidad, me dice con su tonito perverso, tendría que escribir sobre vos y yo. Quizá la escriba". La coda de esta entrada revierte nuevamente el ataque sobre la revista de la Universidad de Belgrano: “[Osvaldo Lamborghini] Está ligado a la revista Vigencia, que hace la política cultural de la dictadura y publica notas abominables de Marta Lynch exaltando la hombría de [Emilio] Massera" (2017, p. 142).

No sería aventurado suponer que esa nota encargada a Lamborghini -que nunca llegó a publicarserecayera finalmente en César Aira: allí están Asís y Piglia, sobresaliendo del resto, para corroborarlo; así como la mención de "los buenos novelistas" que cierra el artículo: Manuel Puig, Juan José Saer, Nicolás Peyceré y... Osvaldo Lamborghini con Sobregondi retrocede (1973).

Esta querella literaria o guerra de posiciones, como la llama Piglia en otra entrada de Los diarios..., ${ }^{3}$ ha sido estudiada en distintos textos críticos que abordan la obra de Aira y analizan la polémica nota de Vigencia (Contreras, 2002; Porrúa, 2005; Fernández, 2010). Pero ninguno de ellos se detiene a situar su contexto de publicación y, menos aún, a explicitar sus vínculos con el gobierno de facto. Este trabajo pretende saldar esa deuda, mediante una indagación pormenorizada de la revista, que busca confrontar las tajantes definiciones que formula Ricardo Piglia a través de Emilio Renzi. Esas escenas lejanas que vuelven en una obra cuya edición fue estrictamente planificada para 2017 vinculan de manera directa a dos escritores hoy canónicos de la literatura argentina con la política cultural de la dictadura. Ellas no agotan, claro está, el contenido ni las funciones de la revista, pero al apuntar hacia Aira y Fogwill, invitan a examinarla en su conjunto. 


\section{Breve historia de Vigencia: origen y vínculos con el "Proceso"}

La revista Vigencia nació en setiembre de 1968 como órgano cultural de la Universidad de Belgrano (fundada en 1964). Su director, desde su fundación, fue el sociólogo y profesor de esta casa de estudios, Rubén H. Zorrilla, bajo la firma editorial de su rector, el Dr. Avelino José Porto. Se trataba, en esta etapa inicial, de una revista de aparición bimensual, que constituía una empresa cultural netamente académica y aspiraba a "proyectarse como instrumento de divulgación interdisciplinaria para convertirse, no solo en órgano de la Universidad que le da origen, sino en herramienta de construcción crítica y constructiva”, como reza su primer editorial (Porto, 1968, p. 2). Las colaboraciones provenían fundamentalmente del ámbito académico y versaban sobre derecho, psicología, educación, economía, antropología, música, cine, literatura, entre otras ramas del saber universitario y la vida cultural en general. Al cabo de doce números, en diciembre de 1970, la revista dejó de aparecer sin explicitar los motivos, y resurgió en mayo de 1977, con un renovado formato de periódico tabloide y una serie de cambios sustanciales orientados hacia un proyecto periodístico masivo, bajo la dirección de Porto. Si bien esta segunda etapa guarda poca relación con la primera, puede observarse una línea de continuidad entre ambas en un decisivo giro de timón que tomó la publicación en el antepenúltimo número de la primera época:

Vigencia es una forma de desmentir la idea de un divorcio entre los problemas concretos de la sociedad y la pasión de conocimiento de la universidad. Por eso ahora se abre también a temas tradicionalmente excluidos de una revista universitaria: el político, el económico y el sindical. Vigencia cambia, pero no la idea rectora sobre la cual desarrolla su vida: convertirse en "tribuna" objetiva y universal del pensamiento humano (Porto, 1970, p. 9).

En efecto, esta apertura a la actualidad política anunciada en 1970 y truncada dos meses después debido a la discontinuación de la revista será definitoria de la segunda época de Vigencia. La revista vuelve al ruedo en los primeros meses de 1977, cuando se ha cumplido un año de la instauración del régimen dictatorial encabezado por el general Jorge Rafael Videla, autodenominado "Proceso de Reorganización Nacional”, y en el marco de una anunciada apertura del diálogo cívico-militar, con vistas a iniciar un debate interno que permitiera gestar una propuesta política a futuro. Vale recordar que por entonces el presidente de facto anunció el fin de la “etapa de silencio" y el inicio del "diálogo", que incluía la promesa de arribar a una democracia representativa, republicana y federal, como indica el documento que habían presentado las Fuerzas Armadas ante la opinión pública en enero de 1977, titulado Bases para la intervención de las fuerzas armadas en el Proceso Nacional. En el mes de abril, Videla anunciaba la intención de "abrir un diálogo a toda la comunidad nacional que solamente reconoce como exclusiones al corrupto, al delincuente económico y al delincuente subversivo" y anunciaba la presentación de una "Propuesta de unión nacional" (Canelo 2005: 70). En este contexto, reaparece Vigencia con un proyecto que se pretende pluralista (el editorial inicial repite a modo de slogan y en tipos de imprenta "SUMAR IDEAS") e independiente: "Vigencia no es la propuesta de ninguna corriente de poder ni de intereses particulares. No representa a grupos ni sectores ocultos" (Porto, 1977a, p. 3).

Si bien la inclusión de la agenda política fue paulatina, ya en el primer año de esta nueva etapa puede relevarse, en distintas colaboraciones, un manifiesto aval a la intervención militar, que expresaba el consenso inicial que amplios sectores de la opinión pública prestaron al gobierno de facto. En el primer número, Manuel V. Ordóñez, fundador del Partido Demócrata Cristiano y activo participante de la Revolución Libertadora, señalaba en una nota dedicada a la Declaración Universal de los Derechos del Hombre:

En el orden interno la subversión guerrillera y económica desconoce los derechos humanos; pero los invocan ella y sus secuaces para condenar la represión gubernamental en esta guerra revolucionaria que ella provocara, y que, como todas las guerras, es sucia, como ha dado en calificársela, y pasible de arbitrariedades y errores (1977, p 6).

Y en el número 3 podía leerse la siguiente declaración de Carlos Durero, periodista encargado de política internacional, que, claro está y como es usual, expresaba libremente la opinión del firmante sin comprometer la responsabilidad editorial: 
1976 es, en ese orden de ideas, inédito. La intervención es decidida por los jefes de las tres fuerzas. El objetivo es la ocupación de Estado para rescatarlo de sus crisis, en un clima de guerra interior como no había existido en ninguno de los casos precedentes y en medio de un proceso caótico difícilmente comparable al más dramático de sus antecedentes (1977, p. 5).

Vigencia habilitó sus columnas a un nutrido grupo de intelectuales liberal-conservadores que contribuyeron a dotar al gobierno militar de una orientación ideológica y programática. Es el caso de Jaime Luis Perriaux, abogado, estudioso de filosofía del derecho y uno de los principales discípulos argentinos de José Ortega y Gasset, quien había sido ministro de Justicia durante las presidencias de Levingston y Lanusse y era el promotor del grupo Azcuénaga, un círculo de políticos, economistas e intelectuales de derecha asociados a grandes empresarios nacionales, que oficiaba de consejero político del ministro de economía José Alfredo Martínez de Hoz (Novaro y Palermo 2003: 201). También podemos sumar a este grupo al filósofo Jorge L. García Venturini, quien se desempeñó como director General de Cultura de la provincia de Buenos Aires e interventor de Eudeba. Algunos colaboradores de Vigencia participaron en distintos eventos culturales vinculados al grupo Azcuénaga, como el encuentro internacional "Diálogo de las culturas" organizado por Victor Massuh, embajador argentino ante la Unesco, en Villa Ocampo, en diciembre de 1977 o el Primer Congreso Nacional de Intelectuales, organizado por el Secretario de Cultura, Raúl Alberto Casal, en octubre de $1978 .{ }^{4}$ Otros colaboraban también en la revista Carta política, dirigida por Mario Grondona y frecuentada por los jefes militares, que integraba un conjunto de firmas con pretensiones de convertirse en intelectuales orgánicos del "Proceso", como Raúl Cuello, José Luis de Imaz, Juan Carlos de Pablo y Rodolfo Pandolfi (Álvarez 2006/2007, p. 83).

En general, Vigencia respondía al rol que la dictadura militar propugnaba para la prensa: "una prensa 'moderada' que se posicionara en el 'justo medio' y se moviera dentro de ciertos 'límites de disenso'" (Saborido y Borrelli, 2011, p. 7); lo que el director de Vigencia llamaba en un temprano editorial el "equilibrio responsable" (Porto 1977b, p. 3). En verdad, este eufemismo traducía una estrategia de omisiones deliberadas en torno a temas como la tortura y la represión clandestina, lo que sumado a la voluntad dialoguista con el régimen consolidó una política de autocensura en relación a los temas sensibles que pudieran afectar el capital político de las Fuerzas Armadas. El discurso de Vigencia podría incluirse entre aquellos que confiaban en la intención de las Fuerzas Armadas de normalizar la vida democrática del país y apostaban a un gobierno de convergencia cívico-militar.

En ocasiones, la cúpula militar eligió las páginas de Vigencia para exponer sus posiciones, como en la entrevista al jefe de la Armada, comandante Armando Lambruschini, realizada por Roberto García en junio de 1980. La bajada de esta nota expresa indirectamente el carácter de interlocutor válido que revestía la publicación para el gobierno de facto, en tanto mediadora o nexo entre el poder militar y la opinión pública:

No es habitual el acceso periodístico a los miembros de la Junta Militar. Mucho menos al representante y máximo jefe de la Armada, su Comandante Armando Lambruschini. [...] Pero esos hombres, que han debido adaptar su personalidad en algunos casos a la naturaleza ética de su función, no son inaccesibles. Y, como corresponde, de vez en cuando eligen una tribuna -a través de discursos o reportajes- para puntualizar una línea de pensamiento o esclarecer los objetivos del Proceso que presiden (García 1980, p. 8).

Una decidida apologista de la dictadura militar surgió de entre las filas de escritores que reportaban en Vigencia: la popular autora de best sellers, Marta Lynch. La escritora fue convocada por primera vez en ocasión de cumplirse el segundo aniversario del "Proceso", para brindar su opinión sobre la política económica de Martínez de Hoz. Allí se declaraba lega en asuntos económicos, pero dispuesta a responder la consulta de Vigencia "con el sentido común compartido por 25 millones de argentinos" (1978a, p. 9). ¿Qué decía este supuesto "sentido común"? Que la Argentina había estado enferma y su cuerpo había sido atacado y corroído en su moral (la metáfora médica tan cara a la dictadura cívico-militar); que el reclamo del almirante Massera por los territorios perdidos en la Patagonia debido a errores diplomáticos era digno de elogio; que los sectores populares estaban dispuestos a adoptar una actitud de sacrificio y renunciamiento patriótico; que los argentinos habíamos aprendido a esperar y a respetar a quienes ofrecen un plan determinado. Con 
estos antecedentes Lynch se sumó de manera permanente al equipo de colaboradores de Vigencia, justo a tiempo para celebrar la manifestación popular que coronó la hazaña futbolística del mundial de fútbol de 1978 con una crónica dedicada a destacar el deseo de participación y la unidad del pueblo, más allá de banderas políticas y clases sociales, y a exhortar al gobierno a interpretar y encauzar este grito unánime hacia el destino de grandeza que aguardaba a la Argentina (1978b). Tres meses después apareció la entrevista al recientemente retirado Almirante Emilio Massera que tanto debió irritar a Ricardo Piglia, donde podía leerse esta descripción del ex miembro de la Junta Militar: "Da una curiosa sensación de seguridad, de fuerza íntima, ciega, y sin embargo, bien vectorizada. Tiene fe en sí mismo y quizá por eso es extraordinariamente fácil comunicarse con él. Para mí, astuta observadora en la ficción, fue un placer” (Lynch 1978c, p. 16).

\section{RESEÑA INTELECTUAL Y MATERIAL DE VigenCia}

La segunda época de Vigencia, iniciada en mayo de 1977, trajo consigo un renovado equipo de colaboradores y un diseño gráfico remozado, que incluía a artistas de la talla de Antonio Berni, Roberto Broullon y Leonardo Villareal como ilustradores. Entre los colaboradores más activos durante el primer año figuran Carlos Durero, en política e internacionales; el filósofo Eugenio Pucciarelli, a cargo de la sección "Mitos Políticos"; el ensayista José Isaacson, en temas de cultura y literatura; los economistas Aldo Ferrer y Raúl Cuello; el sociólogo Julio Mafud; el crítico de cine Agustín Mahieu; la crítica de artes plásticas Nelly Perazzo; el poeta Luis Tedesco, a la sazón director de la Editorial de Belgrano; el crítico musical Martín Müller; el periodista de rock Miguel Grinberg; el crítico teatral Emilio A. Stevanovitch; el escritor José Gobello, con colaboraciones sobre tango y lunfardo; y el escritor y humorista Miguel Brascó, a cargo de la contraportada, entre otros.

De aparición mensual, Vigencia apostó en esta segunda época a ampliar la base de sus lectores, como se advierte en la tirada inicial de 20.000 ejemplares con la que inauguró el ciclo, de la cual anunció haber vendido un 70 por ciento. Esto no le impidió sostener el anclaje académico, como puede observarse en el espacio que la revista le presta a las jornadas y coloquios organizados por la Universidad de Belgrano, que convocan a prestigiosos intelectuales. En otras ocasiones, era la misma revista la que reunía a diversas personalidades para dilucidar cuestiones esenciales, como ser la marcha de la economía a dos años de la designación de José Alfredo Martínez de Hoz como ministro, con la participación de Aldo Ferrer, Raúl Cuello, Marta Lynch y Bernardo Neustadt ("El bienio Martínez de Hoz”, n²12); o la consulta por el futuro del país recién iniciado el año 1979, que incluyó la opinión de dirigentes políticos, personalidades de la cultura y economistas como José Luis Imaz, Juan Carlos de Pablo, Italo A. Luder, Francisco P. Manrique, Luis Pan, Eugenio Pucciarelli, y Antonio Trócolli (“Por donde pasa el 79”, n²4).

La Cátedra del Pensamiento Argentino de la Universidad de Belgrano, fundada por Porto en marzo de 1976, fue uno de los semilleros intelectuales que alimentó el staff de Vigencia, comenzando por Enrique Pugliese, coordinador de la cátedra y periodista de amplia trayectoria como columnista político de $L a$ Razón, quien fue a su vez secretario de redacción de Vigencia desde el comienzo de la segunda época, para convertirse más adelante en subdirector y editorialista hasta el final de la publicación. Esta Cátedra organizó una serie de ciclos en torno a diversas temáticas que constituyeron un foro de discusión política, de debate de ideas y propuestas en torno la problemática argentina. El primero de ellos, que contó con la presencia de Bernardo Canal Feijoo, José Luis Romero, Abelardo Arias, Mario Amadeo, Carlos Floria, Norberto Rodríguez Bustamante, entre muchos otros, culminó con la edición de La argentina posible (1976), primer volumen impreso por el sello Editorial de Belgrano. Los encuentros dieron lugar a una serie de libros que conformaron una colección propia ("Colección Cátedra del Pensamiento Argentino"). Uno de ellos, Medios de comunicación social en la Argentina (1977), en el que participan Horacio de Dios, Bernardo Neustadt, Mariano Grondona, Enrique Pugliese, Hugo Gambini, Luis Pan y otros, presenta en la foto que ilustra la tapa y la contratapa un abanico de medios de prensa entre los que figura Vigencia, rodeada de La Nación, 
Crónica, La Prensa, Caras y Caretas, Clarín, La Opinión, La Razón, Redacción, y Confirmado. El dato de color invita a pensar el lugar preeminente con que Vigencia se auto percibía en el concierto de los medios de prensa masivos. Muchas de las personalidades convocadas a los debates de la Cátedra de Pensamiento Argentino, así como otros profesores de la misma Universidad, pasaron a colaborar en Vigencia de forma permanente; entre ellos, Félix Luna, Carlos Fayt, Fermín Chávez y Luis Alberto Romero. En un testimonio retrospectivo, el historiador Félix Luna señalaba, en relación a la propuesta que le hicieran de incorporarse al claustro académico de la UB en 1978, que "era una oferta tentadora porque Belgrano se encontraba por entonces en su pico mayor de prestigio: allí enseñaban los que habían sido echados o no querían estar en la Universidad estatal, y el elenco docente era brillante" (Luna 2004: 238).

Además de sumar a este grupo de intelectuales de trayectoria diversa, Vigencia se nutrió de un conjunto de colaboradores forjados en las experiencias renovadoras del periodismo de los años sesenta y setenta, como Carlos Quirós, quien se desempeñó como secretario de redacción a partir del n²6 (junio de 1979), Roberto García, Luis Gregorich, Miguel Grinberg y Martín Müller que provenían de la redacción de La Opinión; u Osiris Troiani, que había integrado el staff de Primera Plana. Por las secciones literarias "Poesías" y "Ficciones" pasaron a lo largo de sus 84 números autores como Alberto Girri, Enrique Molina, Santiago Kovadloff, Juan Antonio Vasco, Tamara Kamenszain, María Elena Walsh, Miguel Briante, Beatriz Guido, Antonio Di Benedetto, Alberto Vanasco, Bernardo Kordon, Bernardo Verbitski, Eduardo Gudiño Kieffer, María Esther de Miguel, Raúl Gustavo Aguirre, Enrique Anderson Imbert, Liliana Heker, Luis Gusmán, Rodolfo Fogwill, Mario Levrero, Angélica Gorodischer, etc. Muchos de ellos colaboraron también en otras secciones de la revista, que número tras número presentaba un elenco excepcional de escritores, ensayistas y críticos, entre los que merece destacarse el nombre de Jaime Rest. Sin jactancia y sobre bases objetivas, la revista podía publicar, al cumplirse su tercer año de vida, un listado de nombres con más de trescientos cincuenta colaboradores y entrevistados bajo el título de "El pensamiento en Vigencia". Hacia 1980 llegó a contar con un equipo de nueve corresponsales en Barcelona, Brasil, Londres, Pekín, Madrid, Medio Oriente, México, Roma y Venezuela. Entre ellos Sara Gallardo, que enviaba desde Barcelona entrevistas exclusivas realizadas, por ejemplo, a Salvador Dalí o Joan Miró.

Vigencia apuntaba a un lector formado, "el profesional ocupado y preocupado por interpretar la realidad que lo circunda", "el funcionario -sea militar o civil- que pone en marcha una estrategia o una política", "el joven universitario", o "el intelectual extranjero que desee tener una visión independiente”, y se enorgullecía de sus más de seiscientos suscriptores extranjeros, entre los cuales figuraban intelectuales, políticos, economistas y militares ("A nuestros lectores", n 36). Las publicidades acompañaban esta segmentación, con presencia mayoritaria de editoriales, casas bancarias, compañías aéreas, tabacaleras y automotrices. Sus artículos se inscribían en un periodismo de tipo interpretativo que exigía un lector de largo aliento, como aquel que comenta en una carta de lectores: "Vigencia se lee dos veces'. Le dije a mucha gente que algunas de las colaboraciones son como mini-ensayos" ("Lectoras y lectores", $\mathrm{n}^{\circ} 5$ ).

A partir del número 47 (abril de 1981) la revista dio un salto material cualitativo al pasar del formato de periódico tabloide, impreso en hojas de papel prensa en blanco y negro (el uso de un color, por lo general el rojo, estaba reservado para el nombre de la publicación y los titulares de tapa), a un tamaño de revista más estandarizado y maleable (formato carta) con tapas de papel ilustración a color. La transformación incluyó asimismo un crecimiento abrupto de la cantidad de páginas, de 48 a 106, con la consecuente incorporación de nuevos colaboradores y la contratación de servicios especiales de prestigiosas revistas internacionales como Der Spiegel, Le Nouvel Observateur, Magazine Littéraire, The New York Times Magazine, Les Nouvelles Litteraires, Eco, Zona Franca, Opera Mundi y Camera Press. Todo esto contribuyó a acentuar el perfil cultural de la revista, que incluyó a partir de entonces notas firmadas por Vladimir Nabokov, Milan Kundera o Claude Levi-Strauss, y entrevistas a Jean Paul Sartre, Philippe Sollers e Isaac B. Singer, entre otros, en traducciones especialmente realizadas para Vigencia. El nuevo formato sumó además un ilustrador de excepción que dejaría su marca registrada en la serie de tapas que firmó mientras ejerció la función de Director 
de Arte: Hermenegildo Sabat, de reconocida trayectoria en Primera Plana, La Opinión y Clarín. También la fotografía adquirió un espacio autónomo en esta nueva etapa, con la inclusión de una sección interna en papel ilustración y la incorporación de Sara Facio al equipo de colaboradores. Algunas secciones se ampliaron con el nuevo formato, como fue el caso de "Agenda", mezcla de agenda cultural e información miscelánea, y "Libros", la sección dedicada a reseñar las novedades bibliográficas. Esta última ya contaba con un equipo más o menos fijo de colaboradores, entre los que figuraban de manera preeminente poetas del grupo Poesía Buenos Aires como Raúl Gustavo Aguirre, Rodolfo Alonso, Alberto Vanasco y Elizabeth Azcona Cranwell, además de Silvia Verbistski, María Esther de Miguel, Oscar Hermes Villordo y Luis Alberto Romero. Fue con el crecimiento de esta sección que se sumaron nuevas firmas de escritores a la lista de reseñadores, entre ellas las de José Sbarra y César Aira. La renovación de Vigencia trajo a su vez una nueva y efímera sección, "Publicidad y Comunicación", a cargo de un sociólogo, autor de dos libros de versos, uno de cuentos, y de varias novelas inéditas, que ya había debutado en Vigencia con un extraño texto de ficción titulado "El interno que escribe" ( $\left.{ }^{\circ} 49\right)$ : Rodolfo Enrique Fogwill.

\section{Los “VANguardistas" De la Editorial de Belgrano}

Aira y Fogwill comenzaron a colaborar en Vigencia en los meses previos a la salida de sus respectivos libros, Ema, la cautiva -se terminó de imprimir el 19 de octubre de 1981- y Música japonesa -se terminó de imprimir el 26 de agosto de 1982- por Editorial de Belgrano. Evidentemente, existían entre la revista y la editorial universitaria canales de retroalimentación ya que eran los dos pilares de un proyecto cultural común. El listado de colaboradores de Vigencia y el de autores de la editorial guardan numerosas correspondencias. La editorial había sido fundada el 5 de agosto de 1976 y, como se anticipó, sus primeras publicaciones compendiaban las intervenciones en los ciclos de la Cátedra del Pensamiento Argentino de la UB. Pronto las colecciones fueron aumentando y diversificándose. Se sumaron, así: La Argentina Histórica, Ensayos, Textos, Figuras Contemporáneas, Politica internacional, Conflictos y Armonias en la Historia Argentina, Testimonios Contemporáneos, Clásicos Argentinos, hasta llegar a Narradores Argentinos Contemporáneos. El gerente de la editorial era el poeta Luis $\mathrm{O}$. Tedesco, que por entonces ya poseía una reconocida trayectoria como librero y editor ligado a la cadena de Librerías Fausto, donde había concretado, entre otros proyectos, una excelente colección de poesía bilingüe con traducciones de poetas argentinos como Rodolfo Modern, Alberto Girri o Raúl Gustavo Aguirre. La figura de Tedesco es el nodo que articula la presencia de poetas del grupo Poesía Buenos Aires y de escritores como Fogwill y Aira en las páginas de Vigencia. Su actividad en la Editorial de Belgrano constituye, además, un factor de disonancia respecto del alineamiento político de la revista, que, claro está, no fue homogéneo a lo largo de su ciclo. Bajo la dirección de Tedesco la editorial dio un salto cuantitativo en la edición de obras de autores argentinos. Tedesco tenía una estrecha relación con Enrique Pezzoni, por entonces asesor literario de Editorial Sudamericana, quien, según comenta el primero en una entrevista, le enviaba autores que por política editorial no podía publicar en Sudamericana, como por ejemplo Alberto Laiseca, de quien la Editorial de Belgrano publicó Matando enanos a garrotazos (1982). En la misma entrevista Tedesco se enorgullecía -con razón- de haber publicado en esos años "narrativa de la mejor, de una gran parte de los autores hoy más reconocidos" como César Aira, Rodolfo Enrique Fogwill, Isidoro Blaisten, Carlos Gosrostiza, Arturo Cerretani y otros. La labor editorial de Tedesco no estuvo exenta de tensiones hacia el interior de la Universidad de Belgrano, según él mismo testimonia:

Entre el '76 y el '83 el anclaje en la Editorial de Belgrano fue, digamos, "seguro". Lo paradójico fue que publiqué a todos los escritores "contestatarios". Incluso publiqué un libro del hermano de Pacho [Mario] O'Donnell, Guillermo O'Donnell, que se llamó El Estado burocrtico autoritario, que me valió la renuncia a la Universidad de Belgrano, porque algunos amigos del rector, Porto, le dijeron que yo estaba publicando literatura subversiva (Longhi 2002/2003). 
Otro de los libros polémicos editados por Tedesco fue justamente, La seducción de la hija del portero, de Pacho O’Donnell, que había sido publicado originalmente en 1975 por Siglo XXI y contenía un relato (el que da título al volumen) que había generado airadas protestas debido a su supuesto contenido pornográfico. ${ }^{5}$ La contratapa del libro (en la edición de Belgrano) evoca los incidentes del 2 de abril de 1976, cuando Siglo XXI fue allanada, arrasada y clausurada, el mismo día que O'Donnell presentaba su libro en la Feria del Libro de Buenos Aires. Cuando la Editorial de Belgrano lo reeditó, en 1982, al regreso de su autor del exilio, la Editorial Emecé, que tenía a su cargo la distribución de los libros de Belgrano, se negó a hacerlo por su carácter obsceno, lo cual ocasionó un conflicto que puso en riesgo el contrato entre ambas editoriales ( $\mathrm{O}^{\prime}$ Donnell, 2010). Entre los autores censurados por la dictadura militar y publicados por la Editorial de Belgrano en la colección de "Narradores Argentinos Contemporáneos" cabe mencionar también a Eduardo Gudiño Kieffer y a Blas Matamoro, uno de los creadores del Frente de Liberación Homosexual (junto a Juan José Sebrelli, Manuel Puig y Néstor Perongher), que había debido exiliarse en Madrid luego de la censura sufrida por su libro Olimpo (Corregidor, 1976), por atentar "contra los valores de la moral cristiana, de la tradición nacional y del ser argentino fijados por la junta militar en el acta del 24 de marzo de 1976" (Avellaneda, 1986, p. 141).

Los ejemplos citados invitan a reflexionar sobre la heterogeneidad intrínseca del catálogo de la Editorial de Belgrano, lo cual puede hacerse extensivo a la revista Vigencia, fundamentalmente en lo que respecta a las secciones culturales, que proporcionaron una de las notas distintivas de esta publicación.

Los "vanguardistas" de la Editorial de Belgrano, como los definiera Renzi con irónicas comillas en Los diarios..., hicieron un ruidoso desembarco en el número 49 de Vigencia, de junio de 1981. Allí aparece la primera colaboración de César Aira: una reseña del último libro de Julio Cortázar, Alguien que anda por ahí (Bruguera, 1977), cuya distribución en Argentina se había demorado cuatro años debido a la censura. La colección de relatos terminó saliendo por la editorial española porque Cortázar se había negado a la exigencia de la Junta Militar de suprimir dos cuentos: "Segunda vez" y “Apocalipsis de Solentiname” (Alazraki 1994, p. 334). La crítica de Aira se saltea la polémica con Danubio Torres Fierro que había generado este libro a propósito de los cuentos censurados, al igual que esquiva la más reciente polémica que habían sostenido Cortázar y Liliana Heker sobre el conflictivo tópico de exilio y literatura. Esto a pesar de que la reseña se publica junto a otra de Gabriela Massuh sobre Maldición eterna a quien lea estas páginas (Seix Barral, 1980), de Manuel Puig, bajo el título común de "Cortázar, Puig: conjurar la realidad argentina" y una bajada que equiparaba a los dos autores "desde un más o menos justificado autoexilio". Para Cortázar "Segunda vez", un cuento que narra la extraña desaparición de un ciudadano común en una dependencia estatal durante una entrevista burocrática, "contiene en una pocas páginas el horror cotidiano de la Argentina aplastada por la junta militar de Videla, el sistema fríamente atroz que ha acabado con escritores como Haroldo Conti, como Rodolfo Walsh, que ha hecho desaparecer centenares de periodistas y abogados y científicos, y millares de obreros y militantes sindicalistas" (Cortázar, 1994 [1978], p. 158). Para Aira es un cuento "sobre una oficina pública donde se desmaterializa a la gente" (1981b: 68). Para Cortázar, escribir sobre Solentiname -la comunidad campesina nicaragüense que habría de rebelarse contra la dictadura de Somoza, y resultó destruida por la Guardia Nacional del dictador- "era una de las muchas maneras de atacar el oprobio y la opresión en la literatura" (p. 156); para Aira el cuento es "una convincente remake de uno de sus cuentos famosos 'Las babas del diablo'”. La despolitización de los cuentos y la puesta entre paréntesis de los debates polémicos busca devolver a Cortázar al territorio autónomo de la literatura y someterlo a una lectura formal de la que no sale bien parado: su estilo, sus procedimientos, sus preferencias temáticas, sus ideas políticas, todo ha cristalizado en una obra que se repite a sí misma y no constituye más que un "puro deleite para cortazarianos" (Aira 1981b, p. 68).

Por su parte, Rodolfo Fogwill es presentado en el mismo número 49 de Vigencia a través de su texto "El interno que escribe”, en el que narra con sorna su vida como preso en la cárcel de Caseros, donde había purgado una breve condena por un delito de defraudación y estafa contra la empresa tabacalera Nobleza Piccardo. Quizás el aspecto más transgresor del relato -incluido en la sección "Ficciones" - sea la frivolización 
de la vida carcelaria de un escritor en el contexto del terrorismo de estado. Por esos mismos días de invierno de 1981 en que se publicaba el texto de Fogwill, un grupo de escritores, entre ellos Piglia, Rabanal, Juan Carlos Martini Real y Eduardo Belgrano Rawson discutía la redacción de una carta abierta que incluyera una declaración sobre los escritores desaparecidos: "Por lo menos, les digo, hay que hablar de Walsh, de Conti, de Urondo, de Santoro, de Diana Guerrero, de Bustos. Si no, para qué escribirla” (Piglia, 2017, p. 144). Mientras tanto, Fogwill celebraba su estadía en la cárcel, ya que le ofrecía las mejores condiciones posibles para dedicarse a leer y escribir (Zunini, 2014, p. 29). Su postura era desconcertante para algunos, "sospechosa" para otros, tal como comenta Alan Pauls, quien había conocido a Fogwill en este período: "Con los milicos en el poder, vos sabías donde estaban Ricardo Piglia, China Ludmer, Beatriz Sarlo. Con Fogwill no. A mis veinte años, Fogwill era básicamente sospechoso. ¿Para quién trabajaba? Era como un doble agente” (Zunini, 2014, p. 27).

Las dos siguientes colaboraciones de Fogwill remiten a sus saberes publicitarios e inauguran, como se comentó, una nueva sección de Vigencia ("Publicidad y comunicación”): "La utopía consumerista" ( ${ }^{\circ}$ 50) y "La ficticia realidad" ( $\left.\mathrm{n}^{\circ} 51\right)$. Es en este último número donde aparece "Novela argentina: nada más que una idea”, segunda colaboración de Aira en la revista y segundo ajuste de cuentas, esta vez con los novelistas jóvenes contemporáneos que están produciendo en el país. Su tercera intervención crítica no se hace esperar y eleva la apuesta, ya que toma como objeto a la literatura argentina en su conjunto, con la excusa de realizar una encuesta "privada" (entiéndase: con un único encuestado, el propio Aira) sobre una cuestión más bien frívola: “Quién es el más grande de los escritores argentinos?” ( $n^{\circ} 53$ ), según reza el título de la nota. En este ensayo breve de impar agudeza crítica, Aira recurre al concepto de literatura menor, tal como lo desarrollaron Deleuze y Guatari (1978 [1975]) en su análisis de la obra de Kafka, para trazar una línea divisoria al interior de la literatura argentina de los siglos XIX y XX. Los rasgos que caracterizan a una literatura menor son retomados en sede local para distinguir entre lo mejor y lo peor escrito en nuestro país. Por un lado, una literatura menor plenamente lograda, esto es, una literatura en conflicto permanente, hecha en una lengua no autóctona, donde cada problema individual se vincula de inmediato con lo político y adquiere un valor colectivo. De este lado entonces, los gauchescos, Domingo F. Sarmiento, Lucio V. Mansilla, Macedonio Fernández y Roberto Arlt; y Jorge L. Borges, claro está, de quien Aira afirma que "toda su obra (...) es el trabajo de un operador de una literatura menor" (Aira 1981c: 85). Del otro lado "una supuesta literatura de 'maestros' fallidos": Leopoldo Lugones, Enrique Larreta, Eduardo Mallea, Ernesto Sábato. La respuesta final a la interrogación del título es obvia y coincide con el sentido común del "hombre de la calle": el más grande de los escritores argentinos es Borges. Lo interesante son los motivos (opuestos al sentido común) que Aira esgrime para justificar esta afirmación, a partir de una característica clave que le adjudica a Borges: "el abandono de la individualidad, en favor de lo que llaman [Deleuze y Guatari] 'un dispositivo colectivo de enunciación"”. Aira invoca una serie de personajes de cuentos clásicos para sostener la hipótesis de que lo central en Borges es el "dispositivo para deshacer al escritor en el lector, y viceversa": Pierre Menard, Funes, Dahlmann, Américo Castro, Isidro Parodi. La nota está ilustrada con dos fotografías que sintetizan la hipótesis, una de Borges y otra de Kafka: para Aira, Borges es nuestro Kafka. El mismo mes en que aparece este artículo, la Editorial de Belgrano publica Ema, la cautiva, y lo que aquel expresa parece cobrar un nuevo sentido a la luz de esta novela, como si hubiera sido escrito para explicitar el programa que la obra de su autor viene a cumplir: "La literatura es un asunto de libros, y éstos son objetos peculiares que sirven de programa y modelo de toda ensoñación que involucra una lengua y una civilización. La importancia de estas ensoñaciones, nebulosas como son, es que marcan la vida del hombre sobre la corteza de la tierra (la marcan incluso en las ruinas, en el desierto), y su coeficiente imposible es la historia" (1981c: 84).

Las intervenciones de Fogwill y Aira en Vigencia van mucho más allá de un ataque personal a un escritor en particular, pretenden poner en entredicho el canon literario, producir un reordenamiento, establecer nuevas jerarquías y preparar el terreno para la recepción de sus propias obras. Se trata, si se quiere, de una irrupción vanguardista, en el sentido más lato del término: el que postula la noción de vanguardia como ruptura, y contempla las intervenciones que implican un quiebre, una rebelión contra las formas artísticas dominantes, 
las instituciones, las tradiciones y el gusto hegemónico. El arsenal de esta fuerza de choque se desplegó tanto en los ensayos breves como en las reseñas publicadas en Vigencia y sus efectos no tardaron en manifestarse: en el siguiente número de Vigencia $\left(\mathrm{n}^{\circ} 54\right)$, Elizabeth Azcona Cranwell reseñó con perplejidad el libro Poemas, de Osvaldo Lamborghini (1980), publicado por Tierra Baldía, la mítica editorial de Fogwill; y Aira hizo lo propio con El evangelio apócrifo de Hadattah (1981), de Nicolás Peyceré (n55). ${ }^{6}$

La operación crítica continuó con una intervención de Fogwill que se publica en el marco del primer Anuario de Vigencia, en respuesta a una consigna del director que proponía realizar un balance del año 1981: “¿Cuáles son las manifestaciones de esta cultura [nacional] que aún persisten, más allá de los estragos causados por la crisis económica y la censura? ¿Qué dicen los intelectuales al respecto?” (Porto, 1981, p. 5). La respuesta de Fogwill se tituló "Jardín de letras robadas" y elabora un diagnóstico que comprende a la literatura producida a lo largo del año desde una perspectiva que prioriza el análisis de la industria cultural: premios, ferias, best sellers, adaptaciones cinematográficas, revistas y libros. Entre los éxitos comerciales, Fogwill coloca ladinamente a Flores robadas de los jardines de Quilmes junto a Respiración artificial, y reitera la boutade de Aira sobre Piglia con el añadido de un elogio ambiguo: "la peor novela del mejor escritor de su generación” (1981, p. 97). La conclusión del artículo es que los mejores libros de buena literatura nacional se escriben en los márgenes, "fuera de los géneros y formatos apreciados por la prensa dominical y su público, fuera de los catálogos de las editoriales masivas y lejos de los proyectos de éxito" (1981, p. 99); circulan en fotocopias, como la obra de Osvaldo Lamborghini, Arturo Carrera, Laiseca y Aira o son los worst sellers, como Peyceré y Belgrano Rawson. Todos ellos son secretos a voces entre críticos y autores de vanguardia; todos ellos, como los llama Fogwill, son "narradores de la post-guerra sucia" (2010, p. 104), donde el post debería leerse como un corte con una zona de la literatura argentina producida durante los años de la dictadura que será posteriormente interpretada como un discurso crítico del presente, como ficciones interrogativas de lo real, aunque adopten las formas de la elipsis, la alegoría, la alusión y la figuración (Sarlo, 1987). Fogwill es contundente a este respecto: "En estos libros no hay cosas ni textos rescatables para la obra de reconstrucción que siempre andan vislumbrando los tontos críticos que combinan palabras en los suplementos 'culturales' de Clarin y La Nación. En ellas solo hay lengua y lectura, ésa es su realidad” (2010, p. 104). ${ }^{7}$

Si la buena literatura argentina se producía desde los márgenes, hacía falta un especialista que conociera el terreno y que pudiese adentrarse en él para alumbrar esas gemas subterráneas, y ese es el rol que asumió Fogwill en Vigencia, "especialista en literatura subterránea, underground" según declaró en una encuesta de la misma revista (1983: 59). Como afirma Damián Tabarovsky, escritores como Fogwill y Aira impusieron en los años ochenta un canon totalmente novedoso para entender la literatura argentina, que permitió remover la herencia directa de los años sesenta y propició una nueva forma de leer la literatura contemporánea y de releer a contra-corriente la propia tradición (2018, p. 31-32). Todos los espacios resultaban adecuados para esta campaña en la que estaba comprometido Fogwill en tanto escritor y publicista: encuestas, presentaciones, mesas redondas, reseñas, artículos de opinión. Hacia 1983/84 el espectro de revistas en las que colaboraba Fogwill se amplía hacia nuevas propuestas periodísticas que manifestaban una voluntad de apertura cultural e ideológica, como El Porteño, Primera Plana (segunda época), El Observador, Cerdos y Peces, entre otras: "Por necesidad de dinero y espacio, firmo notas en media docena de revistas. A veces me preguntan, por ejemplo: ‘Así que ahora escribís en El Porteño?', y yo digo que no, que escribo en mi piecita, y que estos -los de El Porteño, los de Vigencia, etc.- se limitan a publicarme" (2010, p. 198). Por lo demás, la vinculación, a través de la firma de Fogwill, de estos dos medios tan opuestos entre sí, uno asociado a la contracultura juvenil, marginal y minoritaria, el otro a la política cultural de la dictadura, invita a reconsiderar el rol que desempeñó Vigencia en el concierto de publicaciones de la época. En efecto, una indagación de la colección completa de la revista permite refrendar el editorial del quinto aniversario de la publicación: "En un país donde la intolerancia parecía doctrina, demostramos con sincera humildad nuestra definitiva confianza en el diálogo pluralista y creador (“Cinco años sumando ideas”, n60, agosto 1982). 


\section{A MODO DE CONCLUSIÓN: UNA HIPÓTESIS DE TRABAJO}

A pesar de sus rasgos contraculturales, las intervenciones de Aira y Fogwill aquí relevadas no se expresaron en circuitos de disidencia intelectual contra el régimen militar ni en las abundantes publicaciones underground que circularon durante la dictadura (Vila, 1985, p. 83). Tampoco se produjeron en espacios culturales y académicos de "catacumbas" (Kovadloff, 1982) sino que lo hicieron en un medio donde se manifestaron posiciones en abierta convivencia con el discurso oficial de la dictadura cívico-militar, que apostaba a la masividad y que había llegado a instalarse en el competitivo mercado de revistas de la Argentina. Si esto entraña una contradicción, su análisis excede los límites de esta indagación. Lo que importa señalar, a modo de conclusión provisoria e hipótesis de trabajo, es la necesidad de extender los estudios del campo cultural del período más allá de la producción intelectual vinculada a un pensamiento o sensibilidad de izquierda, para incluir otras prácticas que, por el hecho de tramarse en medios cercanos al gobierno militar no obtuvieron la misma atención académica. Esto puede deberse a hipótesis históricas muy difundidas, como la de Beatriz Sarlo, quien señaló que el desafío que se planteaba a los intelectuales durante los años del "Proceso" era el de "construir, desde los márgenes, desde el underground, algunas alternativas de futuro para la cultura argentina” (1988, p. 105). Desde esta perspectiva, se trataba de construir un espacio alternativo para la vida intelectual, que permitiera mantener vivo el tejido cultural y político que el terrorismo de estado estaba arrasando. La pregnancia de esta hipótesis se demuestra en el volumen de investigaciones centradas en los focos de resistencia cultural del período y en el -relativamente- menor interés por trabajar los aspectos culturales de publicaciones como Vigencia, por lo general relegadas a la consideración del medio de comunicación como un actor político y al estudio de las posiciones editoriales frente al gobierno de facto. ${ }^{8}$ De ahí que este trabajo se haya propuesto develar, mediante un acotado estudio de caso, otra trama de la producción intelectual que se expresó en los intersticios de un campo cultural fracturado.

\section{REFERENCIAS}

Aira, C. (1981a). Novela argentina: nada más que una idea. Vigencia, (51), agosto, pp. 55-58.

Aira, C. (1981c). ¿Quién es el más grande de los escritores argentinos? . Vigencia, (53), octubre, pp. 84-85.

Aira, C. y G. Massuh. (1981b). Cortázar, Puig: conjurar la realidad argentina. Vigencia, (49), junio, pp. 68-69.

Alazraki, J. (1994), Hacia Cortázar: aproximaciones a su obra. Barcelona: Anthropos.

Álvarez, E. (2006/2007). Los intelectuales del 'Proceso'. Una aproximación a la trama intelectual de la última dictadura militar. Políticas de la memoria, (6-7), verano, pp. 79-85.

Avellaneda, A. (1986). Censura, autoritarismo y cultura: Argentina 1960-1983/2. Buenos Aires: Centro Editor de América Latina.

Canelo, P. (2005). Los fantasmas de la 'convergencia cívico-militar'. Las Fuerzas Armadas frente a la salida política durante la última dictadura militar (Argentina, 1976-1981). Cuadernos del CISH,(17-18), pp. 67-98. Disponible en: http://www.fuentesmemoria.fahce.unlp.edu.ar/art_revistas/pr.3597/pr.3597.pdf

Contreras, S. (2002). Las vueltas de César Aira. Rosario, Argentina: Beatriz Viterbo Editora.

Cortázar, J. (1994) [1978]. Para Solentiname. En Obra critica /3, Buenos Aires: Alfaguara.

Chitarroni, L. (1993). Narrativa: nuevas tendencias. Relato de los márgenes. Cuadernos Hispanoamericanos, (517-519), pp. 437-444.

De Diego, J. L. (2007). ¿Quién de nosotros escribirá el Facundo? Intelectuales y escritores en Argentina (1970-1986). La Plata: Ediciones Al Margen.

Deleuze, G. y F. Guattari (1978 [1975]). Kafka. Por una literatura menor. México: Ediciones Era.

Durero, C. (1977). Los que mandan. Vigencia, (3), julio, pp. 4-5. 
Fernández, N. (2010). Aira. Orbis Tertius, año 15, (16). Disponible en: http://www.fuentesmemoria.fahce.unlp.edu .ar/art_revistas/pr.4237/pr.4237.pdf

Fogwill, R. (1981). Jardín de letras robadas. Vigencia, (55), diciembre, pp. 97-99.

Fogwill, R. (1983). ¿Qué aportaron los marginales a la última década?. Vigencia, (75), diciembre, pp. 59-60.

Fogwill, R. (2010). Los libros de la guerra. Buenos Aires: Mansalva.

García, R. (1980). Lambruschini: 'la Armada no amenaza ni provoca'. Vigencia, (38), junio, pp. 8-11.

Kovadloff, S. (1982). Una cultura de catacumbas y otros ensayos. Buenos Aires: Botella al Mar.

Longhi, L. (2002/2003). Aquella construcción interminable (Reportaje a Luis Tedesco). La idea fija, 5. Disponible en: https://www.laideafija.com.ar/larevista/numero05/TEDESCO_reportaje.html.

Luna, F. (2004). Encuentros a lo largo de mi vida. Buenos Aires, Argentina: Sudamericana.

Lynch, M. (1978a). Marta Lynch: respuesta de una ciudadana a una pregunta extravagante. Vigencia, (12), abril, pp. $8-9$.

Lynch, M. (1978b). ¡Campeones!. Vigencia, (15), julio, pp. 4-5.

Lynch, M. (1978c). Marta Lynch escritora entrevista a Massera ciudadano. Vigencia, (18), octubre.

Morresi, S. (2009). Los compañeros de ruta del Proceso. El diálogo político entre las Fuerzas Armadas y los intelectuales liberal conservadores. XII Jornadas Interescuelas / Departamentos de Historia. Universidad Nacional del Comahue. Bariloche. Disponible en: https://www.aacademica.org/000-008/1157

Novaro, M. y Palermo, V. (2006). La dictadura militar 1976-1983: del golpe de Estado a la restauración democrática. Buenos Aires: Paidós.

O’Donnell, P. (2010). Por izquierdista y pornógrafo. La Nación, 8 de mayo.

Ordoñez, M. V. (1977). El siglo XX y la promoción humana. Vigencia, (1), mayo, pp. 6-8.

Piglia, R. (2017). Los diarios de Emilio Renzi. Un dia en la vida. Barcelona: Anagrama.

Porrúa, A. (2005). César Aira: implosión y juventud. Punto de Vista, XXVIII, (21), abril, pp. 24-29.

Porto, A. J. (1968). Por qué Vigencia. Vigencia (primera época), (1), setiembre-octubre, p. 2.

Porto, A. J. (1970). Otra respuesta. Vigencia (primera época), (10), octubre, p. 9.

Porto, A. J. (1977a). La idea de Vigencia. Vigencia, (1), mayo, p. 3.

Porto, A. J. (1977b). Carta del Director. Vigencia, (5), setiembre, p. 3.

Porto, A. J. (1981). Nuestro primer Anuario. Vigencia, (55), diciembre, p. 5.

Saborido, J. y M. Borrelli (coord.) (2011). Voces y silencios. La prensa argentina y la dictadura militar (1976-1983). Buenos Aires: Eudeba.

Sarlo, B. (1987). Política, ideología y figuración literaria. En D. Balderston y otros, Ficción y política. La narrativa argentina durante el proceso militar. Buenos Aires: Alianza.

Sarlo, B. (1988). El campo intelectual: un espacio doblemente fracturado. En S. Sosnowski (comp.), Represión y reconstrucción de una cultura: el caso argentino. Buenos Aires: Editorial Universitaria de Buenos Aires.

Tabarovsky, D. (2018). Literatura de izquierda. Buenos Aires, Argentina: Ediciones Godot.

Vila, P (1985). Rock nacional, crónicas de la resistencia juvenil. En E. Jelin (comp.), Los nuevos movimientos sociales/1. Buenos Aires: Centro Editor de América Latina.

Zunini, P. (2014). Fogwill: una memoria coral. Buenos Aires: Mansalva.

\section{Notas}

1 Universidad de Buenos Aires. Consejo Nacional de Investigaciones Científicas. Instituto de Historia Argentina y Americana “Dr. Emilio Ravignani”. Facultad de Filosofía y Letras. Ciudad Autónoma de Buenos Aires. República Argentina. El trabajo fue financiado por la Universidad de Buenos Aires. Programación Científica 2018-2020. Proyecto 
trienal UBACYT 200201701 00728BA: "Pasando revista” y por la Agencia Nacional de Promoción Científica y Tecnológica. Proyecto PICT 2016-1226: “Literatura, revistas culturales y prensa en la Argentina (1880-1950)".

2 Una década antes del trabajo de Contreras, el artículo de Aira había merecido un agudo comentario crítico de parte de Luis Chitarroni, en un artículo que trazaba un panorama de las nuevas tendencias en la narrativa argentina contemporánea: "Narrativa: nuevas tendencias. Relato de los márgenes" (1991).

3 “Viernes 7 de agosto. Enfrentado con los 'vanguardistas' de la editorial de la Universidad de Belgrano y con los realistas onda Centro Editor, me muevo en un territorio inestable pero mantengo la guerra de posiciones y el campo propio" (2017, p. 146).

4 Véase la "Carta del Director", Vigencia, (8), diciembre 1977.

5 En este cuento se narra un estupro cometido contra una niña de catorce años, con descripciones explícitas de sus genitales.

6 Las reseñas de César Aira para Vigencia se completan con: "Paisajes, por Luis O. Tedesco" (n 56, enero 1982) y "Las viejas fantasiosas, por Elvira Orphée” (n 57, febrero 1982).

7 Las citas de Fogwill corresponden al artículo "Las aventuras de la escuela de Viena", recopilado en Los libros de la guerra, y erróneamente referenciado a la revista Vigencia, año 1982.

8 Véase a título de ejemplos los estudios dedicados a las revistas Confirmado, Redacción y Extra (Saborido y Borrelli, 2011). 